\title{
Babesia divergens
}

National Cancer Institute

\section{Source}

National Cancer Institute. Babesia divergens. NCI Thesaurus. Code C122179.

A species of intraerythrocytic protozoan parasites in the family Babesiidae. B. divergens is transmitted by the tick Ixodes ricinus and it is the main causative agent of bovine babesiosis. 